doubt by now experiments of this kind will have been repeated and vastly extended. It is essential for the peaceful development of atomic energy that knowledge of this kind should be made available without delay.

G. Pontecorvo

\section{APPLIED STATISTICS}

Statistics for Technologists

By C. G. Paradine and B. H. P. Rivett. Pp. vii + 288. (London: English Universities Press, Ltd., 1953.) 25s. net.

Statistical Methods in Electrical Engineering By Dr. D. A. Bell. Pp. viii + 175. (London : Chapman and Hall, Ltd., 1953.) 25s. net.

NY book on statistical methods for a special A group of readers is vulnerable from two directions - its development of the subject itself, and its suitability for the class of reader at which it is aimed.

"Statistics for Technologists" develops fairly logically those parts of the theory of statistics which its authors include. (Unfortunately, work-study teams wrestling with congestion problems will find no help here.) The approach could be improved, however, by more explanation of the general principles involved in significance testing. The authors are obliged, in their chapter on sampling inspection schemes, to mention briefly the two types of error involved in significance testing, and it would be helpful if some more detailed discussion of these underlying ideas could be inserted before the demonstration of particular tests.

It is perhops a general criticism that although most engineers and scientific workers could comfortably digest the mathematics used, the basic statistical ideas, which are more difficult for the non-statistician to grasp, merit a little further explanation. Also, the way in which the examples are used to illustrate the text is not entirely satisfactory in a book specifically for technologists. Although many of these examples come from technological sources, on the whole they lack the circumstantial information which would illustrate to the student the sort of difficulties involved in practical application. It may be argued that applying theory requires only common sense, but common sense is greatly helped by the experience of others. With these reservations, this book is an adequate introduction to statistical methods for the mathematically minded reader, whether technologist or not.

In contrast, "Statistical Methods in Electrical Engineering" can scarcely be considered as in any way satisfactory in its present form. The result of narrowing the topies discussed to the field of electrical engineering has been to destroy continuity in the treatment of statistical methods. Only in the last two chapters, where the author deals with electrical fluctuations and information theory, does the book become at all convincing. The looseness of construction of the previous chapters can only result in confusing the reader who does "not wish to embark upon a statistician's course of study". For example, the author needs to use Bayes's theorem to derive the expression for the information content of a signal. He therefore discusses Bayes's theorem in his first chapter on probability, and states that it is controversial; but the quotations from Fisher and Jeffreys do not make it clear that it is the assump- tions necessary to apply Bayes's theorem that cause disagreement, nor does he state what these assump. tions are. Again, the use of the word parameter to describe the sample variance and "Student's $t$ " will be irritating to the statistician and confusing to the non-statistician. It has perhaps even confused the author, for he makes the statement that "the random error of the answer deduced from the total of $(N)$ observations is approximately $\sqrt{ } N$ times less than if one relied on a single experiment (actually $\sqrt{N-1}$, which tends to $\sqrt{ } N$ when $N$ is large)". The omission of any discussion of congestion theory is even more noteworthy in this book than in the previous one, for the greater part of the theory was developed by Erlang and his successors specifically for electrical engineers concerned with telephone exchange problems, and an up-to-date definitive text has still to appear. Finally, it is surely superfluous in the appendix listing statistical tables to devote three separate sections to the different forms in which the normal integral is tabulated.

F. DOWNTON

\section{AUTOMATIC DIGITAL CALCULATING MACHINES}

\section{Automatic Digital Calculators}

By Dr. Andrew D. Booth and Dr. Kathleen H. V. Booth. Pp. vii $+231+4$ plates. (London: Butterworths Scientific Publications, 1953.) 32s. net.

ATOMATIC digital calculating machines, though A increasing in number and variety, are still not very numerous and are still news, rather sensational in the public mind. The idea that a calculation involving many digits can be performed in a matter of milliseconds is one that implants despair in certain temperaments, and breeds a curious brand of mechanical mysticism in others. The remedy for such reactions is to read a straightforward and objective book on the historical development and present status of such calculation; and for this purpose the book under notice seems admirable. The authors have the practical and theoretical qualifications, experience with different types of computing machine, enthusiasm for the subject, and a clear and unassuming style of exposition.

The historical introduction is brief, so far as it refers to dates earlier than 1940. The initiator is, of course, Charles Babbage, whose wilful face stares from the pages of any history of calculation, a man whose imagination was exact regarding the possibilities of machine calculation, but far ahead of the mechanical resources available in his own age; a man unable, however, partly through temperament, to retain the sympathy of the government of the time or the continuation of financial support. His ambitions foundered in 1842 ; so that it was almost a century before the coming of electronic techniques enabled those dreams to be more than realized. The third chapter of this book summarizes the rapid advances that took place between 1940 and 1950 .

Several chapters of a descriptive kind follow, in which the technicalities of input, output, control and the various operations, addition and subtraction, multiplication, division and others of miscellaneous nature, are detailed in the clearest manner with excellent diagrams. Chapters on storage follow, and here unfortunately the word 'memory', with its misleading anthropomorphic associations, seems entrenched in the literature and hard now to dislodge. 